\title{
Penerapan E-Learning Menggunakan Media Edmodo dalam Pembelajaran Fisika Berbasis Nilai Karakter untuk Meningkatkan Hasil Belajar pada Konsep Usaha dan Energi
}

\author{
N. A. Haruna, D. G. E. Setiawan, A. H. Odja* \\ Prodi Pendidikan Fisika, Fakultas Matematika dan Ilmu Pengetahuan Alam, Universitas \\ Negeri Gorontalo, Indonesia \\ * Email: abdulharisodja@gmail.com
}

Received: November $7^{\text {th }}, 2020$. Accepted: February 10th 2021. Published: February 28th 2021

\begin{abstract}
Abstrak
Penelitian ini bertujuan untuk menguji penerapan e-learning menggunakan media edmodo dalam pembelajaran fisika berbasis nilai karakter untuk meningkatkan hasil belajar siswa pada materi usaha dan energi. Jenis penelitian ini adalah eksperimen, dengan menggunakan desain One Group PretestPosttest Design. Instrumen yang digunakan dalam penelitian ini berupa soal pretest dan posttest yang terdiri atas 12 nomor soal untuk menguji peningkatan hasil belajar siswa menggunakan $e$ learning dengan menggunakan media edmodo. Uji normalitas data nilai pretest mengggunakan Uji Kolmogorov-Smirnov diperoleh hasil 0.035, dan untuk nilai posttest diperoleh 0.457 . Hasil penelitian menunjukkan peningkatan hasil belajar siswa dengan nilai rata-rata gain 0.82 yang termasuk dalam kriteria tinggi. Hasil analisis hipotesis data yang diperoleh dari nilai pretest dan posttest berdasarkan output "test statistic" diketahui Asymp. Sig (2-tailed) bernilai 0.00. (<0.05). Berdasarkan hasil uji hipotesis dapat disimpulkan bahwa terdapat peningkatan hasil belajar siswa dengan meggunakan e-learning menggunakan media edmodo dalam pembelajaran fisika berbasis nilai karakter pada materi usaha dan energi.
\end{abstract}

\begin{abstract}
This study aims to test the application of e-learning using edmodo media in learning physics based on character values to improve student learning outcomes in work and energy
\end{abstract}


materials. This type of research is an experiment, using the One Group Pretest-Posttest Design design. The instrument used in this study was a pretest and posttest questions consisting of 12 question numbers to test the improvement of student learning outcomes using e-learning using edmodo media. The pretest value data normality test using the Kolmogorov-Smirnov test resulted in 0.035 , and for the posttest value obtained 0.457 . The results showed an increase in student learning outcomes with an average gain value of 0.82 which is included in the high criteria. The results of the data hypothesis analysis were obtained from the pretest and posttest values based on the output "statistical test" known to Asymp. Sig (2-tailed) is 0.00. $(<0.05)$. Based on the results of the hypothesis test, it can be concluded that there is an increase in student learning outcomes by using e-learning using edmodo media in physics learning based on character values on business and energy materials. C2021PERJ

Keywords: e-Learning; Edmodo Media; Character Value; Learning Outcomes.

\section{PENDAHULUAN}

Undang-undang Republik Indonesia No. 20 Tahun 2003 menyatakan bahwa Pendidikan nasional memiliki tujuan dalam mengembangkan potensi siswa agar menjadi manusia yang beriman dan bertakwa kepada Tuhan Yang Maha Esa, memiliki etika, berakal, imajinatif, mandiri, dan membentuk anggota negara yang memiliki sikap demokratis serta bertanggung jawab. Berdasarkan fungsi dan tujuan pendidikan nasional, sudah jelas bahwa pendidikan di setiap jenjang termasuk Sekolah Menengah Atas (SMA) perlu diselenggarakan secara sistematis untuk menggapai suatu tujuan. Hal tersebut memiliki kaitan dalam pembentukan karakter siswa sehingga terbentuk sikap yang mampu bersaing, etika yang baik, memiliki moral, serta sikap beradab dan santun dalam jalinan dengan masyarakat. Pendidikan pada tingkat Sekolah Menengah Atas harus mampu menanamkan pendirian karakter sehingga mampu bersaing, memiliki budi pekerti, bermoral, sopan santun dan mampu menjalin hubungan yang baik dengan masyarakat.

Pandemi Covid-19 yang terjadi saat ini menyebabkan aktivitas pembelajaran tidak dapat dilaksanakan secara tatap muka, dan diharuskan untuk melaksanakan pembelajaran secara online (Arota et al., 2020). Pembelajaran online menurut Waryanto (2006) merupakan pembelajaran dengan 
memanfaatkan jaringan internet sebagai metode penyampaian, interaksi dan fasilitas serta didukung oleh berbagai bentuk layanan belajar lainnya, sehingga siswa dapat belajar lebih luas, lebih banyak dan bervariasi. Pembelajaran online ini menjadi tantangan tersendiri bagi guru maupun siswa, karena belum terbiasa melaksanakan pembelajaran selain tatap muka di kelas. Pembelajaran online menimbulkan masalah bagi guru dalam menyampaikan materi, maupun bagi siswa dalam menerima materi. Salah satu masalah yang muncul yaitu pembelajaran dari guru ke siswa yang monoton hanya dengan pemberian tugas tanpa penjelasan materi sehingga siswa tidak dapat memahami materi dengan baik (Mutia \& Leonard, 2013).

Berdasarkan permasalahan yang timbul karena pembelajaran online, diperlukan alternatif untuk memperlancar proses pembelajaran. Alternatif yang bisa digunakan adalah dengan menggunakan metode berbasis e-learning dalam pembelajaran yang dapat memicu keaktifan siswa (Puspitasari, Astuti \& Masturi., 2020). Pembelajaran berbasis e-learning dapat dilakukan pada jarak jauh dengan simulasi materi yang akan dipelajari (Hanum, 2013). Penelitian Mulyani (2013) menyatakan bahwa pembelajaran berbasis e-learning berpengaruh terhadap hasil belajar siswa.
Guru dan dosen diharapkan dapat memanfaatkan teknologi secara optimal untuk memfasilitasi aktivitas pembelajaran yang inovatif. Strategi dan metode pembelajaran yang berpusat pada siswa diperlukan untuk mendorong pengembangan pengetahuan dan skill siswa. Siswa tidak cukup hanya mengetahui informasi dan mengingat fakta, tetapi harus dapat berpikir kritis dan menyelesaikan permasalahan, serta memiliki skill untuk berkomunikasi dan bekerja sama (Fariyani \& Kusuma, 2021). Selain itu, siswa harus mampu beradaptasi, mempunyai inisiatif, mampu mengakses dan menganalisis informasi serta mempunyai keingintahuan tinggi (Arota et al., 2020).

Hasil observasi yang telah dilakukan di sekolah menunjukkan bahwa intensitas penggunaan laptop/gadget yang terkoneksi dengan internet lebih diutamakan untuk mengakses media sosial dan game online dibanding mengakses materi pembelajaran. Tanpa disadari, jika terus digunakan, penggunaan internet akan berpengaruh signifikan terhadap prestasi belajar siswa. Salah satu cara untuk mengurangi dampak negatif penggunaan internet adalah dengan memaksimalkan e-learning untuk menunjang pembelajaran di sekolah (Hadjarati et al., 2020).

Pemanfaatan teknologi informasi e-learning yang dapat digunakan melalui web ataupun aplikasi untuk pembelajaran akan membawa 
perubahan yang sangat baik dalam pembelajaran (Rulviana, 2018). Edmodo merupakan salah satu aplikasi yang dapat digunakan sebagai media pembelajaran online. Edmodo merupakan sebuah platform pembelajaran sosial yang didesain khusus untuk dunia pendidikan dengan tampilan mirip facebook yang praktis, mudah dan dapat digunakan langsung oleh dosen/guru, siswa dan mahasiswa maupun untuk orang tua/wali (Putri et al., 2017). Edmodo memiliki berbagai macam fitur yang dapat membantu kelancaran pembelajaran, seperti: Note/catatan yang dapat terbaca oleh siswa;

Assignment/Penugasan, yaitu fitur bagi guru untuk memberikan penugasan kepada siswa dengan batasan waktu tertentu; Quiz/kuis, yang memberikan kemudahan untuk membuat berbagai jenis kuis yang dapat dikerjakan oleh siswa, seperti kuis benar salah, pilihan ganda, jawaban singkat, dan mencocokan. (Usman, 2016; Karimah et al., 2018; Marimuthu et al., 2017).

Edmodo dapat digunakan sebagai media pembelajaran online untuk berbagai materi, termasuk usaha dan energi. Materi usaha dan energi membutuhkan penjelasan, simulasi, dan latihan/kuis agar siswa dapat memahami konsep dengan baik. Penggunaan platform edmodo sangat sesuai untuk kebutuhan ini. Selain itu, berdasarkan wawancara dengan guru fisika, hasil belajar siswa pada materi usaha dan energi juga termasuk dalam kategori rendah sehingga memerlukan media yang dapat meningkatkan motivasi dan hasil belajar siswa, khususnya pada masa pembelajaran jarak jauh. Oleh karena itu, perlu dilakukan penelitian tentang penerapan $e$ learning menggunakan edmodo dalam pembelajaran berbasis karakter untuk meningkatkan hasil belajar siswa pada konsep usaha dan energi.

\section{METODE}

Penelitian ini termasuk jenis quasi eksperimen dengan menggunakan One Group Pretest-posttest Design, yaitu terdapat pretest sebelum siswa diberi perlakuan dan posttest setelah diberi perlakuan. Instrumen yang digunakan berupa tes dalam bentuk esai. Teknik analisis data untuk pengujian peningkatan hasil belajar menggunakan uji $\mathrm{N}$-gain.

\section{HASIL DAN PEMBAHASAN}

Hasil analisis uji N-gain untuk menentukan peningkatan hasil belajar siswa disajikan pada Tabel 1 . Berdasarkan hasil yang ditunjukkan pada Tabel 1, hasil belajar siswa mengalami peningkatan dari sebelum dan sesudah penerapan $e$ learning. Uji gain juga dilakukan pada setiap level kognitif soal dengan membandingkan skor setiap level kognitif soal pretest dan posttest pada pembelajaran e-learning. Hasil 
uji gain pada tiap level kognitif dari $\mathrm{C} 1, \mathrm{C} 2, \mathrm{C} 3$, dan C4 disajikan pada Gambar 1.

Tabel 1. Rekapitulasi Nilai Tes Hasil Belajar Siswa

\begin{tabular}{|c|c|c|c|c|}
\hline \multirow[b]{2}{*}{$\begin{array}{c}\text { Jenis } \\
\text { Tes }\end{array}$} & \multirow{2}{*}{$\begin{array}{c}\text { Nilai } \\
\text { Maks / } \\
\text { Nilai } \\
\text { Min }\end{array}$} & \multirow[b]{2}{*}{$\begin{array}{l}\text { Rata } \\
\text {-rata }\end{array}$} & \multicolumn{2}{|c|}{$<\mathrm{g}>$} \\
\hline & & & $\begin{array}{l}\mathrm{N}- \\
\text { gain }\end{array}$ & Kriteria \\
\hline pretest & $\begin{array}{l}47.2 \\
1.92\end{array}$ & 25 & & \\
\hline posttest & $\begin{array}{l}98.88 \\
52.23\end{array}$ & 76 & 0.82 & Tinggi \\
\hline
\end{tabular}

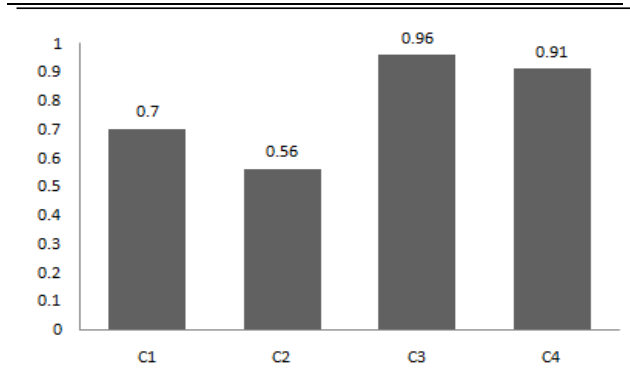

Gambar 1. N-Gain Setiap Level Kognitif Soal

Hasil analisis pada tiap level kognitif menunjukkan bahwa peningkatan dengan kategori tinggi terdapat pada level C1, C3, dan C4, sedangkan level C2 termasuk kategori sedang. Pembelajaran $e$ learning bergantung pada pengelolaan pembelajaran dengan memanfaatkan berbagai aplikasi ataupun web yang cocok untuk digunakan. Penelitian yang dilakukan oleh Mulyati (2013) menyatakan bahwa aplikasi joomla cocok digunakan untuk pembelajaran e-learning. Selain kemudahan dalam instalasi dan pengolahan aplikasi, joomla juga dapat mengembangkan dan mengelola website secara cepat dengan tidak mengesampingkan fitur-fitur dan keindahan tampilan yang sangat beragam.

Pembelajaran e-learning dengan edmodo juga baik dan cocok digunakan untuk pembelajaran online karena selain aplikasinya yang memiliki kemiripan seperti facebook sehingga pemula dapat menggunakan secara cepat, edmodo juga memiliki banyak fitur yang dapat digunakan untuk pembelajaran dan fitur tersebut sesuai dengan kebutuhan siswa dan guru. Hal ini sesuai dengan pendapat Dwiharja (2015) bahwa pemanfaatan edmodo selain untuk meningkatkan efisiensi, juga untuk mengatasi keterbatasan ruang dan waktu.

Penggunaan edmodo yang telah dimanfaatkan secara meluas guna meningkatkan professionalitas guru, tak lepas dari kreativitas seorang guru untuk mengelola belajar mengajar virtual secara efektif. Pada pembelajaran elearning, siswa dapat belajar dari jarak jauh. Siswa juga bisa belajar setiap saat, selain waktu yang sudah ditetapkan untuk melakukan pembelajaran secara bersamaan; artinya siswa dapat melakukan proses pembelajaran sesuai dengan keinginannya karena dalam pembelajaran e-learning telah disediakan video materi yang akan dipelajari sehingga siswa yang masih kurang memahami materi dapat mempelajari lagi dimanapun dan kapanpun. Selain itu, siswa juga 
dapat menambah wawasan mengenai materi dengan melakukan browsing di google.

Pada pembelajaran e-learning dengan menggunakan media edmodo, diberikan soal-soal dan kuis untuk melihat sejauh mana pemahaman siswa mengenai materi. Siswa harus mampu mengerjakan kuis dan soal secara mandiri karena di setiap kuis dan soal sudah ditentukan waktu untuk mengerjakan sehingga siswa yang mengerjakan di luar waktu yang ditentukan tidak dapat lagi mengerjakan karena soal dan kuis tersebut akan tertutup otomatis dan tidak dapat dilihat lagi. Hal ini meminimalisir siswa untuk saling menyontek karena berpacu dengan waktu, begitupun dalam mengerjakan soal pretest dan posttest.

Kondisi seperti ini berpengaruh dalam pembelajaran e-learning karena dapat memberikan dampak positif terhadap hasil belajar siswa. Sesuai dengan pendapat Suharyanto \& Mailangkay (2016), elearning mengubah model pembelajaran tradisional menjadi visual sehingga guru dapat menyediakan bahan-bahan pelajaran untuk siswa, mengontrol materi yang diajarkan, mengeksplorasi kegiatan masingmasing peserta seperti absensi online, pengumpulan tugas online, dan lain-lain.

Terdapat perbedaan yang signifikan hasil belajar siswa sebelum menggunakan e-learning menggunakan media edmodo dan sesudah menggunakan e-learning menggunakan media edmodo. Hal ini menunjukkan bahwa pembelajaran e-learning menggunakan media edmodo berpengaruh terhadap hasil belajar siswa. Pengalaman belajar melalui pengamatan secara langsung melatih penalaran ilmiah dan menjadikan pembelajaran lebih bermakna (Susilawati, et al., 2020).

Nilai-nilai karaker yang ditanamkan pada saat pembelajaran yaitu pada saat pembukaan dengan menuliskan salam (religius), pemberian bahan ajar (rasa ingin tahu dan tanggung jawab), pelaksanaan diskusi (toleransi dan tanggung jawab), pemberian kuis dan tugas (jujur, mandiri, disiplin dan tanggung jawab). Menurut Kamus Besar Bahasa Indonesia, karakter diartikan sebagai tabiat; sifat-sifat kejiwaan, akhlak atau budi pekerti yang membedakan seseorang dengan yang lain; watak, sedang kata berkarakter diterjemahkan sebagai mempunyai tabiat, mempunyai kepribadian, berwatak. Kamus psikologi menyatakan bahwa karakter adalah kepribadian ditinjau dari titik tolak etis atau moral, misalnya kejujuran seseorang. Karakter mempunyai kaitan dengan sifat-sifat yang relative (Jalil, 2016: 8).

Tujuan pendidikan karakter adalah penanaman nilai dalam diri siswa dan pembaruan tata kehidupan bersama yang lebih menghargai kebebasan individu. 
Pendidikan karakter juga bertujuan meningkatkan mutu penyelengaraan dan hasil pendidikan di sekolah yang mengarah pada pencapaian pembentukan karakter dan ahklak mulia siswa secara utuh (Zuriah, 2008).

Nilai-nilai karakter dapat dikembangkan berdasarkan sifatsifat dalam diri sebagai kebiasaan setiap individu yang diterapkan di lingkungan. Nilai-nilai karakter yang dikembangkan sebaiknya disesuaikan dengan lingkungan dan kondisi di sekitar sehingga dapat mengantarkan ketepatan individu dalam berperilaku (Mumpuni, 2012).

Nilai- nilai karakter bertujuan untuk menghasilkan siswa yang berperilaku baik. Kebaikan perilaku yang dimaksud yaitu mewujudkan kepribadian yang bijaksana, beretika, bermoral, bertanggung jawab, berorientasi masyarakat, dan disiplin diri. Nilai-nilai tersebut dapat menjadi dasar pembentukan perilaku bagi setiap manusia. Nilainilai karakter terbentuk dari tiga hal yang saling berhubungan. Ketiga hal tersebut terdiri atas moral knowing, moral feeling, and moral action. Karakter diawali dari pengetahuan terhadap baik atau buruknya nilai-nilai yang diwujudkan dalam tindakan nyata hingga melekat dalam diri seseorang (Mumpuni 2018: 16-17).

\section{KESIMPULAN}

Berdasarkan hasil penelitian dapat disimpulkan bahwa terdapat peningkatan hasil belajar siswa dengan penerapan e-learning menggunakan media edmodo pada pembelajaran fisika berbasis karakter pada konsep usaha dan energi. Pemanfaatan edmodo dapat meningkatkan efisiensi, keterbatasan ruang dan waktu, dapat digunakan skala luas dengan kreativitas dan manajemen guru dalam mengelola belajar mengajar virtual.

\section{DAFTAR PUSTAKA}

Arota, A. S., Mursalin, \& Odja, A. H. 2020. The effectiveness of elearning based on SETS to improve students' critical thinking skills in optical instrument material. Journal of Physics: Conference Series, 1521(2). https://doi.org/10.1088/17426596/1521/2/022061

Dwiharja, L. $\mathrm{M}$. 2015. Memanfaatkan Edmodo sebagai media pembelajaran akuntansi. Seminar Nasional, 332-344.

Fariyani, Q., \& Kusuma, H. H. 2021. Development of Test Instruments to Analyze Higher-Order Thinking Skills Through Science-Based Literacy Learning. JIPF (Jurnal Ilmu Pendidikan Fisika), 6(1), 76. 
https://doi.org/10.26737/jipf. v6i1.1886

Hadjarati, Y. A., Arota, A. S., Mursalin, \& Odja, A. H. 2020. Effectiveness of edmodo to improve senior high school students' creative thinking skills in momentum and impulse topics. Journal of Physics: Conference Series, 1521(2).

https://doi.org/10.1088/17426596/1521/2/022065

Hanum, N. S. 2013. Keefetifan elearning sebagai media pembelajaran (studi evaluasi model pembelajaran e-learning SMK Telkom Sandhy Putra Purwokerto). Jurnal Pendidikan Vokasi, 3(1), 90-102. https://doi.org/10.21831/jpv. v3i1.1584

Jalil, A. 2016. Karakter Pendidikan untuk Membentuk Pendidikan Karakter. Nadwa, 6(2), 175. https://doi.org/10.21580/nw. 2012.6.2.586

Karimah, S., Utami, R., \& Hidayah, N. 2018. Keefektifan Media Pembelajaran Berbasis Edmodo terhadap Kreativitas Mahasiswa. Jurnal Pendidikan Edutama, 5(2), 97. https://doi.org/10.30734/jpe. v5i2.132

Marimuthu, R., Shun Chone, L., Teck Heng, L., Terng, H. F., Mara, U. T., \& Pinang, C. P. 2017. Fostering Better Student Performance Through Online
Collaborative Learning via Edmodo Article Information. International Academic Research Journal of Social Science, 3(1), 2017-2053.

Mumpuni, A. 2012. Integrasi Nilai Karakter dalam Buku Pelajaran Analisis Konten Buku Teks Kurikulum 2018. CV Budi Utama.

Mutia, I., \& Leonard. 2013. Kajian penerapan e-learning dalam proses pembelajaran di perguruan tinggi. Faktor Exacta, 6(4), 278-289.

Putri, S. R., Wahyuni, S., \& Suharso, P. 2017. Penggunaan Media Pembelajaran Edmodo untuk Meningkatkan Aktivitas dan Hasil Belajar Siswa Kelas X Pemasaran di SMK Negeri 1 Jember Tahun Ajaran 2016/2017. Jurnal Pendidikan Ekonomi: Jurnal Ilmiah Ilmu Pendidikan, Ilmu Ekonomi, Dan Ilmu Sosial, 11(1), 111-116.

Rulviana, V. 2018. Implementasi Media Edmodo Dalam Mata Kuliah Pengembangan Kurikulum Sekolah Dasar. Refleksi Edukatika: Jurnal Ilmiah Kependidikan, 8(2), 205-208. https://doi.org/10.24176/re.v $8 \mathrm{i} 2.2361$

Suharyanto, \& Mailangkay, adele B.

L. 2016. Penerapan E-Learning Sebagai Alat Bantu Mengajar Dalam Dunia Pendidikan. Jurnal Ilmiah Widya, 3, 17-21. https://doi.org/10.1016/j.neu 
biorev.2016.02.001

Usman, B. 2016. Jurnal Ilmiah Ilmu

Pendidikan, Ilmu Ekonomi, dan Ilmu Sosial. Jurnal EKSIS, 12(1), 3295-3298.

Waryanto, N. H. 2006. Online Learning Sebagai Salah Satu
Inovasi Pembelajaran. In Pythagoras (Vol. 2, Issue 1, pp. 10-23).

Zuriah, N. 2008. Pendidikan Moral dan Budi Pekerti dalam perspektif perubahan. Bumi Aksara. 
Phy. Educ. Res. J. Vol. 3 No. 1 (2021), 65-74 